\title{
Effects of the route of erythropoietin administration on hemoglobin variability and cardiovascular events in hemodialysis patients
}

\author{
Do Hyoung Kim ${ }^{1,2}$, Young-Ki Lee ${ }^{1,2}$, Juhee $\mathrm{Kim}^{1}$, Hayne Cho Park ${ }^{1}$, Kyu Sang Yun ${ }^{1}$, AJin Cho ${ }^{1}$, Jong-Woo Yoon ${ }^{1}$, \\ Ja-Ryong Koo ${ }^{1}$, Jung-Woo Noh $^{1}$ \\ ${ }^{1}$ Department of Internal Medicine, Hallym Kidney Research Institute, Hallym University College of Medicine, Seoul, Republic of Korea \\ ${ }^{2}$ Korean Association for the Study of Renal Anemia and Artificial Intelligence, Seoul, Republic of Korea
}

Introduction: Despite of the routine use of erythropoietin in hemodialysis patients to correct anemia, its administration route's effects on hemoglobin variability and cardiovascular events remain elusive. Herein, we determined different erythropoietin administration routes' effects on hemoglobin variability in hemodialysis patients and the associated factors of hemoglobin variability and cardiovascular events.

Methods: This is a post hoc analysis of a prospective, controlled, randomized, unblinded study with 78 Korean hemodialysis patients receiving intravenous $(n=40)$ or subcutaneous $(n=38)$ erythropoietin therapy. We evaluated hemoglobin variability by calculating the frequency of hemoglobin measurements outside the target range during all visits. The high-frequency group was defined by those with hemoglobin variability over the median value (25\%) while the low-frequency group was defined by those with hemoglobin variability of $<25 \%$.

Results: In this analysis, 37 patients (51.1\%) were male, and the mean age was $50.6 \pm 12.5$ years. The frequency of the value being outside the target hemoglobin range was higher in the subcutaneous group compared to the intravenous group $(p=0.03)$. The low-frequency group required significantly lower erythropoietin doses compared to the high-frequency group. In the adjusted Cox analysis, the parameter high group was a significant independent risk factor for cardiovascular events $(p=0.03)$.

Conclusion: The risk out of the target hemoglobin range increased with subcutaneous administration compared with intravenous erythropoietin administration in hemodialysis patients. An increased frequency of the value being outside the target hemoglobin range was also associated with an increased risk of cardiovascular events.

Keywords: Anemia, Cardiovascular diseases, Erythropoietin, Renal dialysis

Received: December 17, 2020; Revised: April 30, 2021; Accepted: June 6, 2021

Editor: Tae-Hyun Yoo, Yonsei University, Seoul, Republic of Korea

Correspondence: Young-Ki Lee

Department of Internal Medicine, Hallym University College of Medicine, 1 Singil-ro, Yeongdeungpo-gu, Seoul 07441, Republic of Korea.

E-mail:km2071@hallym.or.kr

ORCID: https://orcid.org/0000-0003-3464-6144

\section{Jong-Woo Yoon}

Department of Internal Medicine, Chuncheon Sacred Heart Hospital, Hallym University College of Medicine, 77 Sakju-ro, Chuncheon 24253 , Republic of Korea. E-mail:yoonjw@hallym.or.kr

ORCID: https://orcid.org/0000-0002-7915-3733

Copyright (@ 2021 by The Korean Society of Nephrology

(a) This is an Open Access article distributed under the terms of the Creative Commons Attribution Non-Commercial and No Derivatives License (http:// creativecommons.org/licenses/by-nc-nd/4.0/) which permits unrestricted non-commercial use, distribution of the material without any modifications, and reproduction in any medium, provided the original works properly cited. 


\section{Introduction}

Anemia is a common complication in end-stage renal disease (ESRD) patients undergoing hemodialysis (HD) and leads to a poor prognosis due to cardiovascular complications and increased mortality [1]. After erythropoiesis-stimulating agents had been introduced as treatment options for anemia, the frequency of blood transfusions decreased and the quality of life improved in patients with $\operatorname{ESRD}[2,3]$. The Kidney Disease Outcomes Quality Initiative (KDOQI) guidelines from the National Kidney Foundation recommend maintaining an appropriate hemoglobin $(\mathrm{Hb})$ target of 11 to $12 \mathrm{~g} / \mathrm{dL}$ in HD patients, while Hb values above 13 $\mathrm{g} / \mathrm{dL}$ should be avoided [4]. However, in patients undergoing HD, it is difficult to maintain Hb levels in the adequate range for various reasons such as blood loss during dialysis, iron deficiency, malnutrition, chronic inflammation, secondary hyperparathyroidism, and insufficient dialysis doses. Therefore, only $30 \%$ of patients are within the target range while the others over- or undershoot the recommended target rage [5]. Although the degree of $\mathrm{Hb}$ variability has decreased over the past 10 years [6], it remains a very common issue among HD patients, increasing the risk of overall mortality in these patients [7-9].

Erythropoietin (EPO) administration is one of the main treatment options for anemia in patients with ESRD. However, the effects of the EPO administration route on Hb variability and cardiovascular outcomes in HD patients remain controversial. Recent studies have reported an increase in all-cause mortality in patients with high $\mathrm{Hb}$ variability $[6,7,10]$. Another study involving 5,037 HD patients found no association between cardiovascular mortality and $\mathrm{Hb}$ variability [11]. We previously reported that the risk of vascular access failure may be greater with subcutaneous (SC) EPO administration compared to intravenous (IV) EPO administration [12]. Since proliferative and other biological actions of EPO on vascular cells may be maximized by sustained EPO receptor activation and SC administration may yield a more sustained activation of EPO receptors than the IV route, SC administration may result in poorer outcomes regarding vascular access. However, cardiovascular outcomes did not significantly differ between the two groups in this study.

In the present study, we investigated the effects of different routes of EPO administration on $\mathrm{Hb}$ variability and the association between $\mathrm{Hb}$ variability and cardiovascular events in maintenance HD patients.

\section{Methods}

\section{Study population}

This is a post hoc analysis of a prospective, controlled, randomized, unblinded study comparing IV administration with the SC administration of EPO [12]. A previous randomized trial was conducted between October 1, 2000 and February 28, 2007 at the Hallym University Kangnam Sacred Heart Hospital and the Hallym University Chuncheon Sacred Heart Hospital in Korea. The enrollment criteria for patients were (1) patients aged 18 years or older receiving HD for more than 6 months, (2) patients receiving regular erythropoiesis-stimulating agents for anemia, and (3) patients with adequate iron storage (transferrin saturation $\geq$ $20 \%$ and serum ferritin $\geq 100 \mathrm{ng} / \mathrm{mL}$ ). The exclusion criteria were patients with (1) severe hyperparathyroidism (serum intact parathyroid hormone $\geq 800 \mathrm{pg} / \mathrm{mL}$ ), (2) acute infection or systemic underlying inflammatory diseases, malignancy, or epilepsy, (3) severe congestive heart failure (New York Heart Association Classes III and IV), (4) gastrointestinal bleeding in the previous 3 months, (5) platelet count exceeding $500 \times 10^{3} / \mu \mathrm{L}$, (6) pregnancy or lactation, (7) the use of androgens or immunosuppressive drugs during the past 3 months, (8) blood transfusion within 2 months before enrollment in the study, or (9) a history of hypersensitivity to EPO.

This study was approved by the Institutional Review Board of Hallym University Kangnam Sacred Heart Hospital (No. 2021-06-005). Due to retrospective nature of the study, the informed consent was waivered. All clinical investigations were conducted in accordance with the guidelines of the 2008 Declaration of Helsinki.

\section{Study design}

Patients were randomly assigned to receive EPO beta (Recormon; F. Hoffmann-La Roche, Ltd., Basel, Switzerland) by either the IV or SC route. Randomization was performed centrally using a random permuted block with stratification according to the clinical center, age ( $\geq 60$ or $<60$ years), and EPO dose (50 to 99, 100 to 149 , or 150 to 
$200 \mathrm{U} / \mathrm{kg} /$ week). Following the enrollment of patients in this study, EPO was administered through IV or SC routes at the same doses that had been administered through the SC route prior to enrollment.

During the study, the EPO dose was increased or reduced by $25 \%$ compared to the previous dose when the $\mathrm{Hb}$ value decreased or increased by at least $1 \mathrm{~g} / \mathrm{dL}$, respectively. When $\mathrm{Hb}$ dropped below $9 \mathrm{~g} / \mathrm{dL}$, the EPO dose was increased by $25 \%$, and when it was increased to at least $12 \mathrm{~g} /$ $\mathrm{dL}$, the dose was reduced by $50 \%$. At the time of enrolling patients in the study, the target $\mathrm{Hb}$ in the KDOQI guidelines was 11 to $12 \mathrm{~g} / \mathrm{dL}$ [4]. However, in the present study, $\mathrm{Hb}$ was titrated within the range of 9 to $12 \mathrm{~g} / \mathrm{dL}$ using the above algorithm to prevent excessive $\mathrm{Hb}$ corrections.

All the patients enrolled in the study received EPO two or three times/week. During the study period, patients were given oral or IV iron as needed (transferrin saturation $<20 \%$ or serum ferritin $<100 \mathrm{ng} / \mathrm{mL}$ ). Blood specimens for laboratory analyses were drawn from the dialysis tubing before HD monthly. Single-pool Kt/V was determined using two-point urea modeling based on the intradialytic decrease in blood urea levels and intradialytic weight loss. It was computed with the use of the following modified rate equation: single-pool Kt/V $=-\ln [(1-$ urea reduction ratio $)$ $-0.008 \times$ session length $]+[4-3.5 \times(1-$ urea reduction ratio)] $\times$ ultrafiltration / postdialysis weight [13].

\section{Evaluation of hemoglobin variability}

$\mathrm{Hb}$ variability was assessed by the frequency exceeding the titrated target $\mathrm{Hb}$ range of 9 to $12 \mathrm{~g} / \mathrm{dL}$. During the entire study period, we measured $\mathrm{Hb}$ at 1 -month intervals to calculate $\mathrm{Hb}$ variability. To evaluate the effects of $\mathrm{Hb}$ variability, we divided the study population into two groups based on whether the frequency of missing the target $\mathrm{Hb}$ exceeded 25\% in an enrolled patient. Furthermore, $\mathrm{Hb}$ cycling was quantified by measuring $\mathrm{Hb}$ excursions defined as a series of decreasing or increasing monthly $\mathrm{Hb}$ values differing by at least $1.5 \mathrm{~g} / \mathrm{dL}$ [14]. In addition, the degree of $\mathrm{Hb}$ variability was calculated by comparing the conventional standard deviation (SD), residual SD, and coefficient of $\mathrm{Hb}$ variation for each group [15]. For the assessment of EPO responsiveness according to the administration route, we used the erythropoiesis-stimulating agent responsiveness index (ERI), calculated as the average weekly EPO dose per $\mathrm{kg}$ body weight divided by the average $\mathrm{Hb}$ level $(\mathrm{ERI}=[\mathrm{EPO}$ / body weight] / Hb) [16]. The laboratory values used in the analysis were baseline values. However, the EPO dose, ferric sucrose dose, ERI, SD, residual SD, and coefficient of $\mathrm{Hb}$ variation were time-averaged values.

The primary outcome was to investigate the degree of $\mathrm{Hb}$ variability according to the $\mathrm{EPO}$ administration route, while the secondary outcome was the occurrence of cardiovascular events according to the $\mathrm{Hb}$ variation. Cardiovascular events were defined as the occurrence of myocardial infarction, heart failure, and stroke.

\section{Statistical analysis}

All normally distributed numerical variables were expressed as the mean $\pm \mathrm{SD}$, whereas variables with skewed distributions were expressed as the median and interquartile range. Analyses of the differences in baseline characteristics according to the route of EPO administration were performed using the t test for continuous variables and the chi-square test for categorical variables. The Kaplan-Meier method was used to compare cardiovascular event-free survival curves, and differences were assessed using the log-rank test. Patients were censored when cardiovascular events occurred. Multivariate Cox regression analysis of cardiovascular event-free survival was performed with adjustments for age, the high-frequency group, diabetes, previous cardiovascular disease, and vintage dialysis (>18 months). Statistical analyses were performed using IBM SPSS version 26.0 (IBM Corp., Armonk, NY, USA). For all analyses, results were considered statistically significant if $\mathrm{p}<0.05$.

\section{Results}

\section{Baseline characteristics}

A total of 78 patients were enrolled and randomly assigned to the IV (40 patients) and SC (38 patients) groups. Among those, seven patients dropped out for the following reasons: five protocol violations; one withdrawal of consent; one history of blood transfusion. Accordingly, 71 patients (38 in the IV group and 33 in the SC group) completed the study. The mean follow-up period was 50.7 months (4-77 months). Thirty-seven patients (51.1\%) were men, and the mean age was $50.6 \pm 12.5$ years. The rate of patients who had diabetes 
mellitus was $35.2 \%$, and the average number of $\mathrm{Hb}$ measurements was $46.8 \pm 27.5$ times.

The baseline characteristics of the two groups were similar except for the intact parathyroid hormone level, which was significantly higher in the IV group compared to the SC group $(95.1 \pm 87.3 \mathrm{pg} / \mathrm{mL}$ vs. $32.7 \pm 33.1 \mathrm{pg} / \mathrm{mL}, \mathrm{p}<0.001)$ (Table 1). In the SC group, $54.5 \%$ of patients received iron treatment, which was significantly higher than the IV group $(\mathrm{p}<0.001)$. There were no differences in administered EPO doses, transferrin saturation, and ferritin levels between the two groups. In addition, there was no significant difference between the two groups in iron saturation or ferritin during the follow-up period.

Hemoglobin variability by the route of erythropoietin administration

When comparing the $\mathrm{Hb}$ variability between the two groups, the frequency of the value being outside the target $\mathrm{Hb}$ range was significantly lower in the IV group than in the SC group ( $0.27 \pm 0.12$ vs. $0.36 \pm 0.19$ per visit, $\mathrm{p}=0.03$ ). However, the conventional SD, residual SD, and coefficient values of the other parameters did not differ between the two study groups $(0.97 \pm 0.23$ vs. $1.02 \pm 0.28, p=0.43 ; 0.90 \pm$
0.23 vs. $0.97 \pm 0.36, p=0.31$; and $0.10 \pm 0.02$ vs. $0.11 \pm 0.03$, $p$ $=0.15$, respectively). When the ERI was evaluated, there was no statistically significant difference between the IV group and the SC group $(10.9 \pm 3.0$ vs. $11.7 \pm 4.8 \mathrm{U} / \mathrm{kg} /$ week $/ \mathrm{g} / \mathrm{dL}$, $\mathrm{p}=0.61)$ (Table 2).

Based on the frequency of the value being outside the target $\mathrm{Hb}$ range, the study population was divided into groups of patients with frequencies above and below $25 \%$, and the differences between these two groups were compared (32 patients in the low-frequency group and 39 patients in the high-frequency group) (Table 3). There was no statistically significant difference in the proportion of diabetes mellitus between the two groups. However, the proportion of diabetic patients in the high-frequency group was $46.2 \%$, which was higher than that of the low-frequency group (21.9\%) ( $p=0.06)$. In the low-frequency group, 19 patients $(59.4 \%)$ received EPO through IV administration and 13 patients (40.6\%) received EPO through SC administration. In the high-frequency group, 19 patients $(48.7 \%)$ received EPO through IV administration and 20 patients (51.3\%) received EPO through SC administration. There was no difference between the two groups according to the route of administration ( $p=0.51)$. The coefficient of $\mathrm{Hb}$ variation was significantly lower in the low-frequency group compared

Table 1. Patient characteristics at baseline

\begin{tabular}{lccc}
\hline Characteristic & Intravenous group & Subcutaneous group & $p$-value \\
\hline No. of patients & 38 & 33 & 0.26 \\
Age $(\mathrm{yr})$ & $49.1 \pm 12.8$ & $52.3 \pm 11.0$ & 0.18 \\
Male sex & $17(44.7)$ & $20(60.6)$ & 0.09 \\
Diabetes mellitus & $10(26.3)$ & $15(45.5)$ & 0.72 \\
Previous cardiovascular disease & $4(10.5)$ & $5(15.2)$ & 0.34 \\
Dialysis vintage (mo) & $45.3 \pm 34.3$ & $37.5 \pm 32.1$ & 0.41 \\
Predialytic SBP (mmHg) & $146.7 \pm 15.5$ & $150.0 \pm 17.7$ & 0.12 \\
Predialytic DBP (mmHg) & $80.0 \pm 4.8$ & $83.0 \pm 11.0$ & 0.96 \\
Hemoglobin (g/dL) & $9.3 \pm 0.8$ & $9.3 \pm 0.9$ & 0.34 \\
Phosphorus (mg/dL) & $4.7 \pm 1.9$ & $4.3 \pm 1.3$ & 0.38 \\
Albumin (g/dL) & $3.8 \pm 0.3$ & $3.7 \pm 0.4$ & 0.54 \\
Hemoglobin A1c (\%) & $6.0 \pm 1.2$ & $6.3 \pm 1.6$ & 0.67 \\
Ferritin (ng/mL) & $201.4 \pm 37.2$ & $205.8 \pm 49.0$ & 0.68 \\
Transferrin saturation (\%) & $50.5 \pm 27.2$ & $51.0 \pm 25.2$ & $<0.001$ \\
Intact-PTH (pg/mL) & $73.9(31.7-143.5)$ & $21.3(11.8-43.3)$ & 0.51 \\
Single-pool Kt/V & $1.40 \pm 0.29$ & $1.36 \pm 0.25$ & $<0.001$ \\
Iron treatment & $1(2.6)$ & $18(54.5)$ & 0.62 \\
Erythropoietin dose (U/kg/wk) & $95.5 \pm 50.0$ & \\
\hline Data exprsse & \\
\end{tabular}

Data expressed as number only, mean \pm standard deviation, number (\%), or median (interquartile range).

DBP, diastolic blood pressure; PTH, parathyroid hormone; SBP, systolic blood pressure. 
Table 2. Hemoglobin $(\mathrm{Hb})$ variability by route of erythropoietin administration

\begin{tabular}{lccc}
\hline Variable & Intravenous group $(\mathrm{n}=38)$ & Subcutaneous group $(\mathrm{n}=33)$ & $\mathrm{p}$-value \\
\hline $\mathrm{Hb}$ of $>12,<9 \mathrm{~g} / \mathrm{dL}(\mathrm{n} /$ visit) & $0.27 \pm 0.12$ & $0.36 \pm 0.19$ & 0.03 \\
$\mathrm{Hb}$ excursion $(\geq 1.5)(\mathrm{n} /$ visit) & $0.20 \pm 0.08$ & $0.17 \pm 0.12$ & 0.27 \\
Standard deviation of $\mathrm{Hb}$ & $0.97 \pm 0.23$ & $1.02 \pm 0.28$ & 0.43 \\
Residual standard deviation of Hb & $0.90 \pm 0.23$ & $0.97 \pm 0.36$ & 0.31 \\
Coefficient of $\mathrm{Hb}$ variation & $0.10 \pm 0.02$ & $0.11 \pm 0.03$ & 0.15 \\
ESA responsiveness index $(\mathrm{U} / \mathrm{kg} /$ week/g/dL) & $10.9 \pm 3.0$ & $11.7 \pm 4.8$ & 0.61 \\
\hline
\end{tabular}

Data expressed as mean \pm standard deviation

ESA, erythropoiesis-stimulating agent.

Table 3. Comparisons of variables by frequency out of the target hemoglobin $(\mathrm{Hb})$ range

\begin{tabular}{|c|c|c|c|}
\hline Variable & Low-frequency group, $<25 \%(n=32)$ & High-frequency group, $\geq 25 \%(n=39)$ & p-value \\
\hline Age (yr) & $51.8 \pm 12.6$ & $49.6 \pm 11.6$ & 0.44 \\
\hline Male sex & $18(56.3)$ & $19(48.7)$ & 0.69 \\
\hline Diabetes mellitus & $7(21.9)$ & $18(46.2)$ & 0.06 \\
\hline Previous cardiovascular disease & $4(14.7)$ & $5(10.8)$ & 0.73 \\
\hline Dialysis vintage (mo) & $45.7 \pm 34.7$ & $38.6 \pm 32.2$ & 0.38 \\
\hline $\mathrm{Hb}(\mathrm{g} / \mathrm{dL})$ & $9.5 \pm 0.8$ & $9.1 \pm 0.9$ & 0.11 \\
\hline Albumin $(\mathrm{g} / \mathrm{mL})$ & $3.7 \pm 0.3$ & $3.7 \pm 0.3$ & 0.67 \\
\hline Calcium (mg/dL) & $8.6 \pm 1.0$ & $8.7 \pm 1.0$ & 0.56 \\
\hline Phosphorus (mg/dL) & $4.7 \pm 1.8$ & $4.4 \pm 1.4$ & 0.55 \\
\hline $\mathrm{Hb}$ A1c (\%) & $5.9 \pm 1.2$ & $6.3 \pm 1.6$ & 0.40 \\
\hline Intact parathyroid hormone (pg/mL) & $80.3 \pm 91.3$ & $57.8 \pm 59.4$ & 0.23 \\
\hline Single-pool Kt/V & $1.40 \pm 0.30$ & $1.37 \pm 0.24$ & 0.62 \\
\hline Ferritin $(\mathrm{ng} / \mathrm{mL})$ & $201.2 \pm 46.7$ & $205.4 \pm 40.0$ & 0.68 \\
\hline Transferrin saturation (\%) & $50.5 \pm 27.6$ & $50.9 \pm 25.2$ & 0.95 \\
\hline EPO administration route, IV & $19(59.4)$ & $19(48.7)$ & 0.51 \\
\hline Erythropoietin dose (U/kg/wk) & $89.9 \pm 48.5$ & $106.1 \pm 54.6$ & 0.20 \\
\hline Ferric sucrose dose (mg/yr) & $81.9 \pm 217.0$ & $95.3 \pm 249.3$ & 0.82 \\
\hline ESA responsiveness index $(\mathrm{U} / \mathrm{kg} / \mathrm{wk} / \mathrm{g} / \mathrm{dL})$ & $9.8 \pm 5.9$ & $11.9 \pm 6.4$ & 0.17 \\
\hline Standard deviation of $\mathrm{Hb}$ & $0.94 \pm 0.17$ & $1.03 \pm 0.30$ & 0.12 \\
\hline Residual standard deviation of $\mathrm{Hb}$ & $0.86 \pm 0.16$ & $1.00 \pm 0.37$ & 0.06 \\
\hline Coefficient of $\mathrm{Hb}$ variation & $0.10 \pm 0.02$ & $0.11 \pm 0.03$ & 0.009 \\
\hline $\mathrm{Hb}$ of $<9 \mathrm{~g} / \mathrm{dL}$ (n/visit) & $0.15 \pm 0.07$ & $0.43 \pm 0.16$ & $<0.001$ \\
\hline
\end{tabular}

Data expressed as mean \pm standard deviation, or number (\%).

EPO, erythropoietin; ESA, erythropoiesis-stimulating agent; IV, intravenous.

to the high-frequency group $(0.10 \pm 0.02$ vs. $0.11 \pm 0.03, p$ $=0.009$ ). In the low-frequency group, the frequency of the lower limit level ( $<9 \mathrm{~g} / \mathrm{dL}$ ) for $\mathrm{Hb}$ was $0.15 \pm 0.07$ (per visit), and in the high-frequency group, it was $0.43 \pm 0.16$ (per visit) with $\mathrm{Hb}$ being significantly more frequent than the lower limit level of $\mathrm{Hb}(<9 \mathrm{~g} / \mathrm{dL})$ in the high-frequency group $(\mathrm{p}<$ 0.001). However, there was no difference in the initial laboratory test, EPO dose, ferric sucrose dose, ERI, conventional $\mathrm{SD}$, and residual SD between these two groups. During the follow-up period, absolute $\mathrm{Hb}$ values did not differ be- tween the two groups. However, the EPO requirement was significantly lower in the low-frequency group compared to the high-frequency group at 12,24 , and 48 months (81.8 \pm 31.9 vs. $114.5 \pm 38.6 \mathrm{U} / \mathrm{kg} /$ week, $\mathrm{p}<0.001 ; 83.4 \pm 19.2$ vs. $112.3 \pm 51.4 \mathrm{U} / \mathrm{kg} /$ week, $\mathrm{p}=0.01$; and $85.9 \pm 34.7$ vs. $126.7 \pm$ $36.7 \mathrm{U} / \mathrm{kg} /$ week, respectively; $\mathrm{p}=0.001$ ) (Fig. 1A). Similarly, the ERI was lower in the low-frequency group than in the high-frequency group at $12,24,36$, and 48 months $(8.8 \pm 3.9$ vs. $12.6 \pm 4.6 \mathrm{U} / \mathrm{kg} /$ week $/ \mathrm{g} / \mathrm{dL}, \mathrm{p}=0.001 ; 8.8 \pm 2.2$ vs. $12.1 \pm$ $5.7 \mathrm{U} / \mathrm{kg} /$ week/g/dL, $\mathrm{p}=0.007 ; 10.5 \pm 3.9$ vs. $13.8 \pm 4.9 \mathrm{U} /$ 

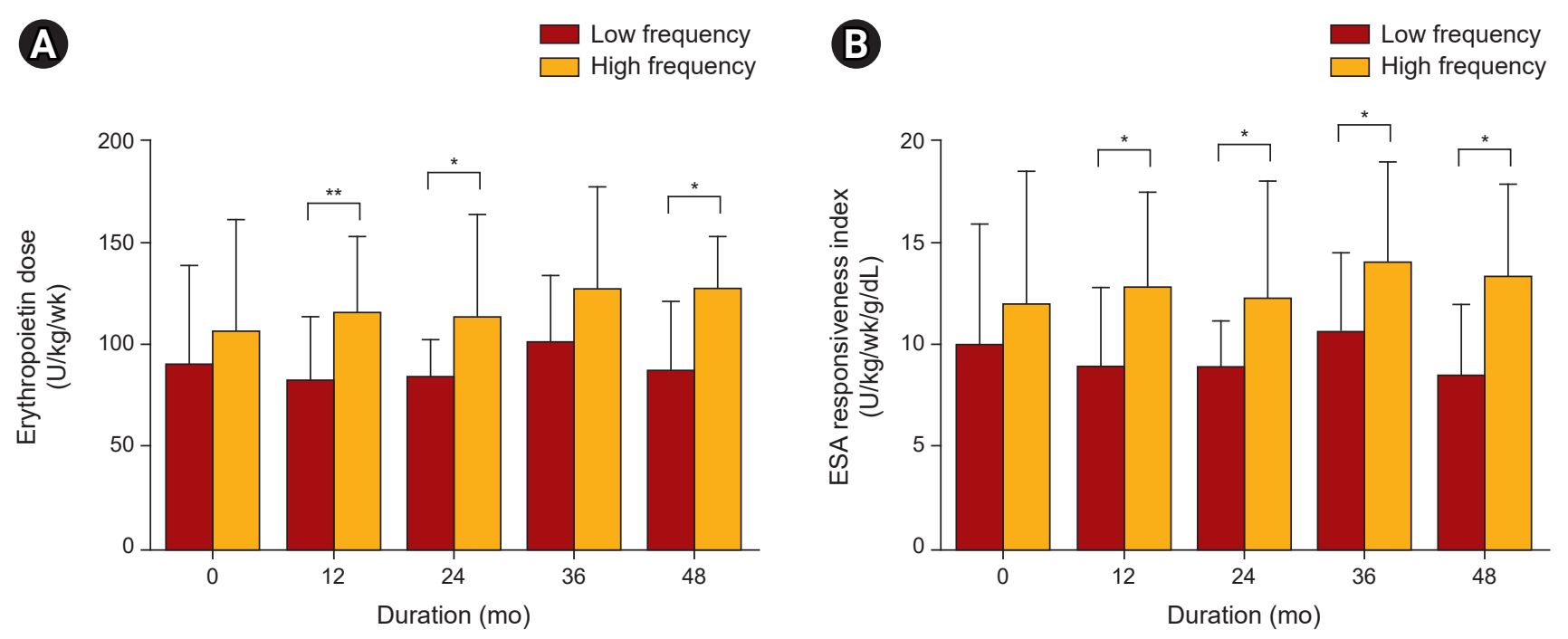

Figure 1. Erythropoietin dose and ESA responsiveness index by frequency out of the target hemoglobin range.

ESA, erythropoiesis-stimulating agent.

$* p<0.05, * * p<0.001$.

Table 4. Univariate and multivariate analysis for the high-frequency group

\begin{tabular}{|c|c|c|c|c|}
\hline \multirow{2}{*}{ Variable } & \multicolumn{2}{|c|}{ Univariate analysis } & \multicolumn{2}{|c|}{ Multivariate analysis } \\
\hline & OR (95\% Cl) & $p$-value & OR (95\% Cl) & p-value \\
\hline Age, $>60 \mathrm{yr}$ & $0.77(0.25-2.36)$ & 0.65 & & \\
\hline Male sex & $0.74(0.29-1.89)$ & 0.53 & & \\
\hline EPO administration route, IV & $0.65(0.25-1.67)$ & 0.37 & & \\
\hline Diabetes mellitus & $3.39(1.19-9.67)$ & 0.02 & $4.49(1.38-14.61)$ & 0.01 \\
\hline Previous cardiovascular disease & $1.27(0.33-4.97)$ & 0.73 & & \\
\hline Dialysis vintage, $>18 \mathrm{mo}$ & $1.76(0.65-4.80)$ & 0.27 & & \\
\hline Hemoglobin & $0.63(0.35-1.11)$ & 0.11 & & \\
\hline Albumin & $0.71(0.16-3.25)$ & 0.66 & & \\
\hline Phosphorus & $0.91(0.68-1.23)$ & 0.55 & & \\
\hline Calcium & $1.15(0.72-1.85)$ & 0.56 & & \\
\hline Intact parathyroid hormone & $1.00(0.99-1.00)$ & 0.24 & & \\
\hline Erythropoietin dose & $1.03(1.01-1.04)$ & 0.002 & $1.03(1.01-1.05)$ & 0.002 \\
\hline Ferric sucrose dose & $1.00(0.99-1.00)$ & 0.87 & & \\
\hline Ferritin & $1.00(0.99-1.01)$ & 0.68 & & \\
\hline Single-pool Kt/V & $0.63(0.11-3.73)$ & 0.61 & & \\
\hline
\end{tabular}

$\mathrm{Cl}$, confidence interval; EPO, erythropoietin; IV, intravenous; OR, odds ratio.

$\mathrm{kg} /$ week $/ \mathrm{g} / \mathrm{dL}, \mathrm{p}=0.02 ; 8.3 \pm 3.5$ vs. $13.2 \pm 4.4 \mathrm{U} / \mathrm{kg} /$ week/ $\mathrm{g} / \mathrm{dL}$, respectively; $\mathrm{p}=0.001$ ) (Fig. 1B). The results of the unadjusted and adjusted logistic regression analyses for the high-frequency group are presented in Table 4 . In the multivariate logistic regression analysis, the presence of diabetes mellitus (odds ratio [OR], 4.49; 95\% confidence interval [CI], 1.38-14.61; $\mathrm{p}=0.01$ ) and EPO dose (OR, 1.03; 95\% CI, 1.01-1.05; $\mathrm{p}=0.002$ ) significantly affected the high-frequen- cy group. However, the route of EPO administration was not related to the high-frequency group.

\section{Hemoglobin variability and cardiovascular outcomes}

During the study period, 19 out of 71 patients (26.8\%) died including nine cases (12.7\%) of cardiovascular events and five cases $(7.0 \%)$ of infection. Cardiovascular events oc- 
curred in 22 patients $(31.0 \%)$ during the study period including six patients in the low-frequency group and 16 patients in the high-frequency group. In the survival analysis, the occurrence of cardiovascular events was significantly higher in the high-frequency group than in the low-frequency group $(\mathrm{p}=0.02)$ (Fig. 2). However, seven patients (21.9\%) died in the low-frequency group and 12 patients $(30.8 \%)$ died in the high-frequency group with no significant difference between the two groups in all-cause mortality (log-rank $\mathrm{p}=0.29$ ). In cardiovascular mortality, there were three (9.4\%) and six patients (15.4\%), respectively, who did not have any significance between the two groups $(\log -$ rank $\mathrm{p}=0.36)$.

The results of the unadjusted and adjusted Cox proportional hazard regression analyses for cardiovascular events are presented in Tables 5. In the adjusted Cox analysis, the high-frequency group (hazard ratio [HR], 2.96; 95\% CI, 1.038.79; $p=0.04$ ), presence of diabetes mellitus (HR, 3.34; 95\% CI, 1.31-8.76; $\mathrm{p}=0.01$ ), vintage dialysis > 18 months (HR, $3.07 ; 95 \% \mathrm{CI}, 1.02-9.21 ; \mathrm{p}=0.045)$, and older age $>60$ years (HR, 2.80; 95\% CI, 1.12-7.02; $\mathrm{p}=0.028$ ) were independent risk factors for the development of cardiovascular events.

\section{Discussion}

This post hoc analysis of a clinical study comparing IV administration with SC administration of EPO showed that the frequency of the value being outside the target $\mathrm{Hb}$ range was associated with the route of EPO administration, and that the high-frequency group was independently associated with cardiovascular events in HD patients.

In this study, there was no difference in the SD, residual $\mathrm{SD}$ of $\mathrm{Hb}$, and coefficient of $\mathrm{Hb}$ variation according to the EPO administration route. Since it is difficult to maintain $\mathrm{Hb}$ values within the narrow target range, we categorized $\mathrm{Hb}$ variability according to the frequency of the value being outside this range (i.e., low-frequency vs. high-frequency groups). Our study showed that patients of the IV group were less frequently outside the target $\mathrm{Hb}$ range compared to those of the SC group. Furthermore, the coefficient of $\mathrm{Hb}$ variation was lower and $\mathrm{Hb}$ was less frequent than the lower limit level of $\mathrm{Hb}(<9 \mathrm{~g} / \mathrm{dL})$ in the low-frequency group.

$\mathrm{Hb}$ variability in HD patients was first described by Lacson et al. [17] and Berns et al. [18] in 2003. Kalantar-Zadeh and Aronoff [15] reported that factors influencing $\mathrm{Hb}$ vari-

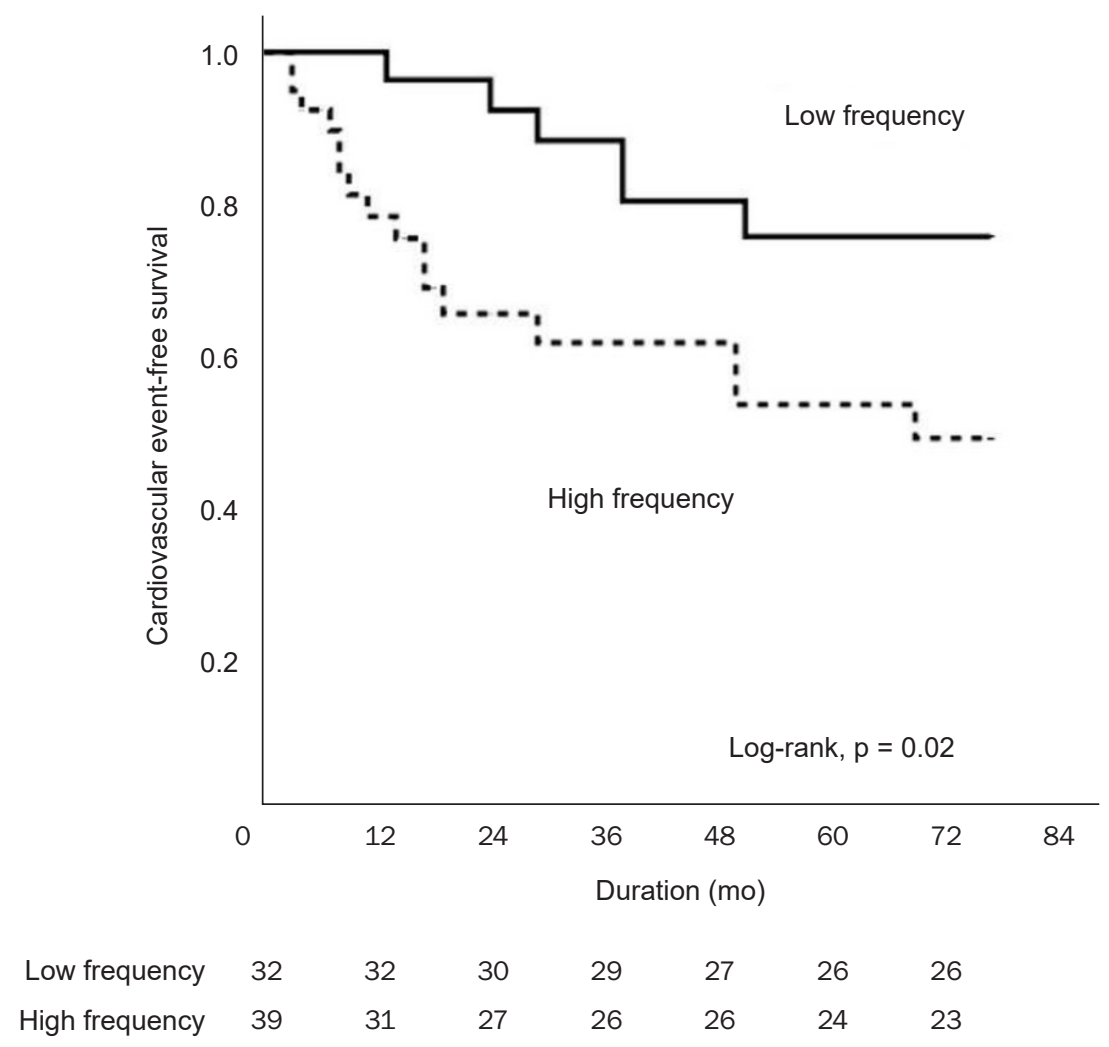

Figure 2. Kaplan-Meier estimates of cardiovascular event-free survival according to hemoglobin variability. 
Table 5. Univariate and multivariate analysis of predictors associated with cardiovascular events according to the out of target range

\begin{tabular}{|c|c|c|c|c|}
\hline \multirow{2}{*}{ Variable } & \multicolumn{2}{|c|}{ Univariate analysis } & \multicolumn{2}{|c|}{ Multivariate analysis } \\
\hline & $\mathrm{HR}(95 \% \mathrm{Cl})$ & p-value & $\mathrm{HR}(95 \% \mathrm{Cl})$ & p-value \\
\hline Age, $>60 \mathrm{yr}$ & $2.44(1.02-5.86)$ & 0.045 & $2.80(1.12-7.02)$ & 0.03 \\
\hline Male sex & $1.03(0.44-2.38)$ & 0.95 & & \\
\hline High-frequency group, $\geq 25 \%$ & $2.93(1.14-7.51)$ & 0.03 & $2.96(1.03-8.49)$ & 0.04 \\
\hline Diabetes mellitus & $4.84(1.96-11.96)$ & 0.001 & $3.34(1.31-8.76)$ & 0.01 \\
\hline Previous cardiovascular disease & $2.92(1.14-7.49)$ & 0.03 & $1.49(0.48-4.68)$ & 0.49 \\
\hline Dialysis vintage, $>18 \mathrm{mo}$ & $3.20(1.08-9.54)$ & 0.04 & $3.07(1.02-9.21)$ & 0.045 \\
\hline Hemoglobin $(\mathrm{g} / \mathrm{dL})$ & $1.18(0.69-2.02)$ & 0.55 & & \\
\hline Albumin (g/mL) & $0.80(0.18-3.52)$ & 0.77 & & \\
\hline Phosphorus (mg/dL) & $0.98(0.76-1.28)$ & 0.90 & & \\
\hline Calcium (mg/dL) & $1.13(0.73-1.74)$ & 0.58 & & \\
\hline Intact parathyroid hormone $(\mathrm{pg} / \mathrm{mL})$ & $1.00(0.99-1.01)$ & 0.88 & & \\
\hline Erythropoietin dose (U/kg/wk) & $1.00(0.99-1.01)$ & 0.62 & & \\
\hline Ferric sucrose dose (mg/yr) & $1.00(0.99-1.00)$ & 0.68 & & \\
\hline Ferritin $(\mathrm{ng} / \mathrm{mL})$ & $1.00(0.99-1.01)$ & 0.63 & & \\
\hline Single-pool Kt/V & $0.32(0.07-1.50)$ & 0.15 & & \\
\hline EPO administration route, IV & $0.49(0.21-1.14)$ & 0.10 & & \\
\hline
\end{tabular}

$\mathrm{Cl}$, confidence interval; EPO, erythropoietin; HR, hazard ratio; IV, intravenous.

ability included drug-related factors, patient characteristics, iron storage, infection, and inflammation. Of these factors, the EPO dose and administration intervals are modifiable factors in the management of HD-associated anemia [19]. In a previous study, Wright et al. [20] reported that the administration of EPO through the SC route reduced the EPO dose, increased its effectiveness, and improved patient outcomes compared to IV EPO administration. By contrast, Bommer et al. [21] reported no differences in $\mathrm{Hb}$ levels and EPO doses between IV and SC administration in HD patients within 48 weeks. Previous studies involved the analysis of the relationship between the route of EPO administration and the degree of $\mathrm{Hb}$ increase, and few studies have directly compared the relationship with $\mathrm{Hb}$ variability.

This study observed the outcome over 51 months using a single formulation of EPO. Therefore, our study exclusively evaluated the impact of the EPO administration route on $\mathrm{Hb}$ variability. Our result is similar to that of the post hoc analysis in a previous study [22]. Patel et al. [22] reported that $\mathrm{Hb}$ variability was slightly higher in SC administration compared to the IV administration of EPO. They suggested that the wide range of bioavailability (18\%-80\%) was large because of differences in absorption from the SC tissue and the specific epoetin-dosing algorithm. In their study, EPO doses were adjusted by an absolute amount rather than as a percentage of the previously prescribed dose. Therefore, EPO administration through the SC route had a longer half-life, and the change in $\mathrm{Hb}$ may have been greater for a given change in EPO dose compared to the IV route. In the present study, the administered EPO dose was determined according to the degree of change in $\mathrm{Hb}$, rather than administering an absolute amount of EPO. Therefore, the relationship between the $\mathrm{EPO}$ administration route and $\mathrm{Hb}$ variability was more accurately evaluated in our study even though similar results were obtained in both studies.

Recent studies have reported an increase in all-cause mortality in patients with high $\mathrm{Hb}$ variability $[6,7,10]$, but no prospective study has analyzed $\mathrm{Hb}$ variability and cardiovascular outcomes to date. In the present prospective study, the frequency of the value being outside the target $\mathrm{Hb}$ range was independently related to cardiovascular events, and the high-frequency group was associated with higher incidences of cardiovascular events.

In our study, $\mathrm{Hb}$ variability did not exhibit a significant association with cardiovascular mortality and all-cause mortality. In a recent meta-analysis, Zhao et al. [7] demonstrated a 9\% increase in the adjusted rate of death for each $1 \mathrm{~g} / \mathrm{dL}$ increase in $\mathrm{Hb}$ variability. However, this relationship between $\mathrm{Hb}$ variability and cardiovascular mortality is inconsistent across studies. Eckardt et al. [11] reported the 
lack of an association between cardiovascular mortality and $\mathrm{Hb}$ variability in 5,037 $\mathrm{HD}$ patients. In their study, $\mathrm{Hb}$ variability was assessed using the parameters within-patient SD, residual SD, and method of fluctuation across the target range (11.0-12.5 g/dL). They also reported that $\mathrm{Hb}$ variability was not related to all-cause mortality in HD patients [11]. By contrast, Lin et al. [23] demonstrated in a retrospective study that high $\mathrm{Hb}$ variability is an independent risk factor for cardiovascular mortality in HD patients. Since the criteria for $\mathrm{Hb}$ variability defined in each study differed and because of the nature of retrospective studies, it is difficult to accurately evaluate the relationship between $\mathrm{Hb}$ variability and cardiovascular mortality.

Unlike previous studies, the current study was conducted as a prospective trial. The high-frequency group was associated with more cardiovascular events and higher $\mathrm{Hb}$ variation compared to the low-frequency group. Although the proportion of diabetic patients did not differ between the two groups, the proportion tended to be high in the high-frequency group. In previous studies, it is known that chronic inflammation, autonomic neuropathy, and microvascular damage caused by diabetes mellitus blunt the response of EPO in chronic kidney disease [24,25]. The proportion of diabetes affects $\mathrm{Hb}$ variability, possibly leading to increased cardiovascular events in the high-frequency group. However, in multivariate Cox analysis, the high-frequency group was related to the occurrence of cardiovascular events independent of the presence of diabetes. This finding suggests that the occurrence of cardiovascular events in HD patients may be related to Hb variability. The high-frequency group tended to exhibit a poor response to EPO and thus, a relatively large amount of EPO was required to reach the target $\mathrm{Hb}$ level, significantly increasing the number of cardiovascular events. Moreover, a high EPO dose has been described as an independent predictor of adverse cardiovascular outcomes [26,27]. Additionally, exogenous EPO can stimulate cellular proliferation and matrix accumulation in blood vessels, increase platelet production and calcium signaling, and contribute to prothrombotic effects. In agreement with this, the incidence of cardiovascular events was high in patients of the high-frequency group even though no correlation between $\mathrm{Hb}$ variability and cardiovascular mortality was observed.

The results of our study should be interpreted with caution given the following limitations. First, this study was a post hoc analysis of a previous randomized controlled trial and was not designed specifically for this aim. Therefore, the sample size may be too small to confirm statistical significance for some observations. Second, at the time the study was performed, laboratory tests to assess inflammatory status, such as C-reactive protein, were not conducted. Third, we studied the response to one EPO formulation. The effects may differ for other EPO formulations. Finally, there was a difference between the target $\mathrm{Hb}$ at the time of the study and the current anemia treatment guidelines. Therefore, further randomized studies on the administration route of EPO according to the current guidelines are necessary.

The strengths of the study are that it is a prospective study and that it has been followed up for a long period of time.

In conclusion, IV EPO administration in HD patients can better maintain $\mathrm{Hb}$ levels within the target range, and a decreased frequency of missing these target values prevents cardiovascular events from occurring.

\section{Conflicts of interest}

All authors have no conflicts of interest to declare.

\section{Authors' contributions}

Conceptualization: YKL, JRK, JWN, JWY

Data curation: DHK, JK, KSY, JRK

Formal analysis: DHK, AJC, HCP

Methodology: DHK, AJC, HCP, YKL, JWN

Supervision: YKL, JWY, JRK, JWN

Writing-original draft: DHK, HCP

Writing-review \& editing: All authors

All authors read and approved the final manuscript.

\section{ORCID}

Do Hyoung Kim, https://orcid.org/0000-0002-8664-8830 Young-Ki Lee, https://orcid.org/0000-0003-3464-6144 Juhee Kim, https://orcid.org/0000-0002-2194-6327 Hayne Cho Park, https://orcid.org/0000-0002-1128-3750 Kyu Sang Yun, https://orcid.org/0000-0001-8019-3938 AJin Cho, https://orcid.org/0000-0001-7097-7026 Jong-Woo Yoon, https://orcid.org/0000-0002-7915-3733 Ja-Ryong Koo, https://orcid.org/0000-0003-4245-2569 


\section{Jung-Woo Noh, https://orcid.org/0000-0002-1743-4695}

\section{References}

1. Cozzolino M, Mangano M, Stucchi A, Ciceri P, Conte F, Galassi A. Cardiovascular disease in dialysis patients. Nephrol Dial Transplant 2018;33(Suppl 3):iii28-iii34.

2. Chapter 3: Use of ESAs and other agents to treat anemia in CKD. Kidney Int Suppl (2011) 2012;2:299-310.

3. Kliger AS, Fishbane S, Finkelstein FO. Erythropoietic stimulating agents and quality of a patient's life: individualizing anemia treatment. Clin J Am Soc Nephrol 2012;7:354-357.

4. IV. NKF-K/DOQI clinical practice guidelines for anemia of chronic kidney disease: update 2000. Am J Kidney Dis 2001;37(1 Suppl 1):S182-S238.

5. Brunelli SM, Lynch KE, Ankers ED, et al. Association of hemoglobin variability and mortality among contemporary incident hemodialysis patients. Clin J Am Soc Nephrol 2008;3:1733-1740.

6. Gilbertson DT, Hu Y, Peng Y, Maroni BJ, Wetmore JB. Variability in hemoglobin levels in hemodialysis patients in the current era: a retrospective cohort study. Clin Nephrol 2017;88:254-265.

7. Zhao L, Hu C, Cheng J, Zhang P, Jiang H, Chen J. Haemoglobin variability and all-cause mortality in haemodialysis patients: a systematic review and meta-analysis. Nephrology (Carlton) 2019;24:1265-1272.

8. Foley RN, Zhang R, Gilbertson DT, Dunning S, Ishani A, Collins AJ. Exceeding hemoglobin target levels in US hemodialysis patients receiving epoetin, 1999 to 2002. Hemodial Int 2007;11:333339.

9. Collins AJ, Kasiske B, Herzog C, et al. Excerpts from the United States Renal Data System 2006 Annual Data Report. Am J Kidney Dis 2007;49(1 Suppl 1):A6-A7, S1-S296.

10. Ghasemi F, Abdi A, Salari N, Tohidi MR, Faraji A. Comparing the effects of intravenous and subcutaneous Erythropoietin on blood indices in hemodialysis patients. Sci Rep 2019;9:2284.

11. Eckardt KU, Kim J, Kronenberg F, et al. Hemoglobin variability does not predict mortality in European hemodialysis patients. $J$ Am Soc Nephrol 2010;21:1765-1775.

12. Lee YK, Koo JR, Kim JK, et al. Effect of route of EPO administration on hemodialysis arteriovenous vascular access failure: a randomized controlled trial. Am J Kidney Dis 2009;53:815-822.

13. National Kidney Foundation. KDOQI clinical practice guideline for hemodialysis adequacy: 2015 update. Am J Kidney Dis 2015;66:884-930.
14. Arneson TJ, Zaun D, Peng Y, Solid CA, Dunning S, Gilbertson DT. Comparison of methodologies to characterize haemoglobin variability in the US Medicare haemodialysis population. Nephrol Dial Transplant 2009;24:1378-1383.

15. Kalantar-Zadeh K, Aronoff GR. Hemoglobin variability in anemia of chronic kidney disease. J Am Soc Nephrol 2009;20:479-487.

16. Chait Y, Kalim S, Horowitz J, et al. The greatly misunderstood erythropoietin resistance index and the case for a new responsiveness measure. Hemodial Int 2016;20:392-398.

17. Lacson E Jr, Ofsthun N, Lazarus JM. Effect of variability in anemia management on hemoglobin outcomes in ESRD. Am J Kidney Dis 2003;41:111-124.

18. Berns JS, Elzein H, Lynn RI, Fishbane S, Meisels IS, Deoreo PB. Hemoglobin variability in epoetin-treated hemodialysis patients. Kidney Int 2003;64:1514-1521.

19. Wish JB. Hemoglobin variability as a predictor of mortality: what's a practitioner to do? Am J Kidney Dis 2011;57:190-193.

20. Wright DG, Wright EC, Narva AS, Noguchi CT, Eggers PW. Association of erythropoietin dose and route of administration with clinical outcomes for patients on hemodialysis in the United States. Clin J Am Soc Nephrol 2015;10:1822-1830.

21. Bommer J, Asmus G, Wenning M, Bommer G. A comparison of haemoglobin levels and doses in haemodialysis patients treated with subcutaneous or intravenous darbepoetin alfa: a German prospective, randomized, multicentre study. Nephrol Dial Transplant 2008;23:4002-4008.

22. Patel T, Hirter A, Kaufman J, Keithi-Reddy SR, Reda D, Singh A. Route of epoetin administration influences hemoglobin variability in hemodialysis patients. Am J Nephrol 2009;29:532-537.

23. Lin FJ, Zhang X, Huang LS, et al. Impact of hemoglobin variability on cardiovascular mortality in maintenance hemodialysis patients. Int Urol Nephrol 2018;50:1703-1712.

24. Pappa M, Dounousi E, Duni A, Katopodis K. Less known pathophysiological mechanisms of anemia in patients with diabetic nephropathy. Int Urol Nephrol 2015;47:1365-1372.

25. Raichoudhury R, Spinowitz BS. Treatment of anemia in difficult-to-manage patients with chronic kidney disease. Kidney Int Suppl (2011) 2021;11:26-34.

26. Szczech LA, Barnhart HX, Inrig JK, et al. Secondary analysis of the CHOIR trial epoetin-alpha dose and achieved hemoglobin outcomes. Kidney Int 2008;74:791-798.

27. Zhang Y, Thamer M, Stefanik K, Kaufman J, Cotter DJ. Epoetin requirements predict mortality in hemodialysis patients. Am J Kidney Dis 2004;44:866-876. 